\title{
Glycogen storage disease due to muscle phosphorylase kinase deficiency
}

INSERM

\section{Source}

INSERM. (1999). Orphanet: an online rare disease and orphan drug data base. Glycogen storage disease due to muscle phosphorylase kinase deficiency. ORPHA:715

Glycogen storage disease due to muscle phosphorylase kinase (PhK) deficiency is a benign inborn error of glycogen metabolism characterized by exercise intolerance. 